Article

\title{
Comparative Study on Kinetics of Ethylene and Propylene Polymerizations with Supported Ziegler-Natta Catalyst: Catalyst Fragmentation Promoted by Polymer Crystalline Lamellae
}

\author{
Zhen Zhang, Baiyu Jiang, Feng He ${ }^{\circledR}$, Zhisheng Fu, Junting Xu@ and Zhiqiang Fan *® \\ MOE Key Laboratory of Macromolecular Synthesis and Functionalization, Department of Polymer Science and \\ Engineering, Zhejiang University, Hangzhou 310027, China; 11329008@zju.edu.cn (Z.Z.); \\ jiangbaiyu827@yeah.net (B.J.); 11329007@zju.edu.cn (F.H.); fuzs@zju.edu.cn (Z.F.); xujt@zju.edu.cn (J.X.) \\ * Correspondence: fanzq@zju.edu.cn; Tel./Fax: +86-571-87952400
}

Received: 12 January 2019; Accepted: 6 February 2019; Published: 19 February 2019

check for updates

\begin{abstract}
The kinetic behaviors of ethylene and propylene polymerizations with the same $\mathrm{MgCl}_{2}$-supported Ziegler-Natta (Z-N) catalyst containing an internal electron donor were compared. Changes of polymerization activity and active center concentration $\left(\left[\mathrm{C}^{*}\right]\right)$ with time in the first $10 \mathrm{~min}$ were determined. Activity of ethylene polymerization was only $25 \%$ of that of propylene, and the polymerization rate $\left(R_{\mathrm{p}}\right)$ quickly decayed with time $\left(t_{\mathrm{p}}\right)$ in the former system, in contrast to stable $R_{\mathrm{p}}$ in the latter. The ethylene system showed a very low $\left[\mathrm{C}^{*}\right] /[\mathrm{Ti}]$ ratio $(<0.6 \%)$, in contrast to a much higher $\left[\mathrm{C}^{*}\right] /[\mathrm{Ti}]$ ratio $(1.5 \%-4.9 \%)$ in propylene polymerization. The two systems showed noticeably different morphologies of the nascent polymer/catalyst particles, with the PP/catalyst particles being more compact and homogeneous than the PE/catalyst particles. The different kinetic behaviors of the two systems were explained by faster and more sufficient catalyst fragmentation in propylene polymerization than the ethylene system. The smaller lamellar thickness $(<20 \mathrm{~nm})$ in nascent polypropylene compared with the size of nanopores $(15-25 \mathrm{~nm})$ in the catalyst was considered the key factor for efficient catalyst fragmentation in propylene polymerization, as the PP lamellae may grow inside the nanopores and break up the catalyst particles.
\end{abstract}

Keywords: ethylene; propylene; Ziegler-Natta catalyst; kinetics; morphology; catalyst fragmentation

\section{Introduction}

After rapid and continuous growth in the last sixty years, the industrial production of polyolefins (polyethylene, polypropylene, and olefin copolymers) has become one of the most important branches of modern chemical industry, and $\mathrm{MgCl}_{2}$-supported Ziegler-Natta $(\mathrm{Z}-\mathrm{N})$ catalysts are playing dominant roles in polyolefin production. Despite extensive fundamental studies in this field over the past decades, there are still many unsolved problems concerning the polymerization mechanism and relationships between catalyst structure and polymerization behaviors. The kinetics and mechanism of ethylene and propylene polymerizations with $\mathrm{Z}-\mathrm{N}$ catalysts have been studied in a broad span of reaction durations ranging from less than $1 \mathrm{~s}$ to more than one hour [1-23]. When ethylene and propylene polymerizations with the same catalyst are compared, several peculiarities in the reaction kinetics have been reported. Y.V. Kissin reported that ethylene polymerization with a $\mathrm{TiCl}_{3}$-based classical Z-N catalyst and $\mathrm{MgCl}_{2}$-supported $\mathrm{Z}-\mathrm{N}$ catalyst both presented build-up type rate curves with a rather long induction period (10-30 $\mathrm{min})$, in which the reaction rate gradually grew to the stationary level. However, propylene polymerization with the same catalyst presented decay type rate curves, in which the reaction rate quickly rose to the maximum and then began descending over a 
long period $[19,20]$. Considering the similar chain initiation and propagation mechanisms of the two monomers and the very fast formation process of the polymerization active centers, it is hard to explain such different kinetic behaviors by a unified mechanistic model [16,24]. It is even more puzzling that ethylene polymerization activity was much lower than that of propylene polymerization when some supported Z-N catalysts containing an internal electron donor were used $[25,26]$. The activity of ethylene polymerization was found to be markedly enhanced by introducing a small amount of propylene before ethylene (so-called prepolymerization) $[25,27,28]$. Because the intrinsic reactivity of ethylene polymerization is evidently higher than that of propylene on the same catalyst [22,25], it is hard to attribute such a phenomenon to certain kinds of chemical activation effect.

V.A. Zakharov et al. studied ethylene and propylene polymerizations with a Ti-based supported Z-N catalyst containing a dibutylphthalate internal donor [25]. They found that the fraction of active centers $\left(\left[\mathrm{C}^{*}\right] /[\mathrm{Ti}]\right.$; here, $\mathrm{C}^{*}$ denotes active center) was larger in ethylene polymerization than in propylene polymerization, and chain propagation rate constants $\left(k_{\mathrm{p}}\right)$ were also larger in the former. The ethylene polymerization activity was markedly enhanced by using a similar catalyst with higher porosity; meanwhile, the activity of the propylene polymerization was not very sensitive to catalyst porosity. The occurrence of diffusion limitation in ethylene polymerization was proposed as the reason for its sensitivity to catalyst porosity. In our previous works, significant enhancement of [C*]/[Ti] with reaction time in the initial stage of ethylene (co)polymerization was observed, and fragmentation of the catalyst particles by hydraulic force of the growing polymer chains was considered the reason for the enhancement of active center numbers [21,22]. According to these results, fragmentation of the catalyst particles significantly influences the $\left[\mathrm{C}^{*}\right] /[\mathrm{Ti}]$ fraction in the initial stage and its changes with time, and thus determines the polymerization kinetics. To explicitly disclose origins of the different reaction kinetics of ethylene and propylene polymerizations, it is thus necessary to directly compare the $\left[\mathrm{C}^{*}\right] /[\mathrm{Ti}]$ versus time profiles of the two systems.

In this work, the microkinetics of ethylene and propylene polymerizations with a supported Z-N catalyst containing a phthalate type internal donor was systematically studied, including tracing the changes of $\left[\mathrm{C}^{*}\right] /[\mathrm{Ti}]$ in the polymerization processes and characterizing the structure of nascent polymer/catalyst particles formed in different reaction periods. The method of counting active centers by quench-labeling the propagation chains with 2-thiophenecarbonyl chloride (TPCC) was used. This method was developed in our laboratory and applied to various olefin polymerization systems catalyzed by both heterogeneous and homogeneous catalysts [21-23,29-34]. The collected results provide new evidence that clearly shows the crucial importance of catalyst particle fragmentation in determining the polymerization kinetics and catalyst efficiency. The knowledge produced through the research can promote an in-depth understanding of olefin polymerization kinetics and mechanism, and guide further optimization of the polymerization process, as well as catalyst development.

\section{Materials and Methods}

\subsection{Reagents}

A commercial supported Z-N catalyst $\mathrm{TiCl}_{4} / \mathrm{Di} / \mathrm{MgCl}_{2}(\mathrm{Ti}$ content $=2.7 \mathrm{wt} \%, \mathrm{Di}=$ dibutylphthalate, provided by SINOPEC Group, Nanjing, China) was used for the polymerization. Triethylaluminum (TEA) was purchased from Albemarle (Charlotte, NC, USA) and used as 2M solution in $n$-heptane. 2-thiophenecarbonyl chloride (TPCC, $>98 \%$ ), purchased from Alfa Aesar Co. (Shanghai, China), was distilled and diluted to $2 \mathrm{M}$ solution in $n$-heptane before use. $n$-Heptane was dried over 4 A molecular sieves under dry nitrogen and refluxed over Na before use. Ethylene and propylene (polymerization grade, supplied by Minxing Gas Co., Hangzhou, China) were purified by molecular sieves and manganese-based deoxygen agent in a gas purification system made by Dalian Samat Chemicals Co., Ltd. (Dalian, China). All other chemicals were obtained commercially and used without further purification unless otherwise stated. 


\subsection{Polymerization and Quenching Reaction}

All operations were carried out under a dry nitrogen atmosphere using standard Schlenk line or glove box techniques. Polymerization runs were conducted in $250 \mathrm{~mL}$ glass reactor equipped with a magnetic stirrer and gas inlet, which was immersed in thermostat bath of $40^{\circ} \mathrm{C}$. After evacuating the reactor and refilling it with monomer gas (ethylene or propylene) three times, the planned amount of $n$-heptane was added to the reactor under the monomer atmosphere. Then, the TEA solution $(\mathrm{Al} / \mathrm{Ti}=40)$ was added, and the calculated amount of catalyst was flushed to the reactor by $n$-heptane to launch the polymerization. Ethylene or propylene flow of $1 \mathrm{~atm}$ pressure was continuously supplied to the reactor for the stipulated polymerization time $\left(t_{\mathrm{p}}\right)$. In the experiments, for the kinetic study, TPCC $($ TPCC $/ \mathrm{Al}=2.5)$ was quickly injected into the reactor after the designed $t_{\mathrm{p}}$ in order to quench the polymerization. After 5 min of quenching reaction, acidified ethanol was added to decompose the catalyst and quencher, and the produced polymer was precipitated with an excess of ethanol. The collected polymer samples were further purified according to the procedures mentioned in our previous work to remove all sulfur-containing impurities $[29,30]$. In the experiments, for studying morphology (SEM observation) and pore size distribution (Brunauer-Emmett-Teller (BET) analysis) of the polymer/catalyst particles, when the calculated $t_{\mathrm{p}}$ was reached, the reactor was quickly immersed in liquid nitrogen to stop the reaction, and then $\mathrm{CO}_{2}$ was bubbled to the reactor to convert TEA into unreactive chemicals, so as to preserve the morphology of nascent catalyst/polymer particles. The particles were vacuum dried at room temperature after removing the solvent, and then stored under nitrogen for SEM and BET analysis.

\subsection{Characterization}

The sulfur content of the quenched polymer was measured with a YHTS-2000 fluorescence UV sulfur analyzer (Jiangyan Yinhe Instrument Co., Jiangyan, China, detection limit $=0.05 \mathrm{ppm}$ ). The polymer sample for the analysis was solid powder $(2-4 \mathrm{mg}$, weighed to $\pm 0.01 \mathrm{mg})$, and the average value of three parallel measurements was recorded for each sample.

Molecular weight and molecular weight distribution of the polymer samples were measured by gel permeation chromatography (GPC) in a PL 220 GPC instrument (Polymer Laboratories, Shropshire, UK) with three PL mixed B columns $\left(500 \sim 10^{7}\right)$ at $150{ }^{\circ} \mathrm{C}$ in 1,2,4-trichlorobenzene. Universal calibration against polystyrene standards was adopted.

Differential scanning calorimetry (DSC) analysis of the polymers was conducted using a TA Q200 DSC instrument under $\mathrm{N}_{2}$ atmosphere. Then, 2-3 mg of each sample was sealed in an aluminum sample pan, and melting endotherm in the first heating scan was recorded at a heating rate of $10^{\circ} \mathrm{C} / \mathrm{min}$ by scanning from 40 to $180{ }^{\circ} \mathrm{C}$.

Scanning electron microscope observations of the PE and PP particles were made with a Hitachi-4800 SEM. Micrographs was taken at $3 \mathrm{kV}$ acceleration voltage. Before SEM observations, all the sample surfaces were vacuum sputtered with a thin layer of gold.

Nitrogen adsorption-desorption isotherms and pore-size distributions of the polymer particles were measured using an AUTOSORB-1-C instrument (Quantachrome, Boynton Beach, FL, USA) at $77 \mathrm{~K}$. Prior to the experiments, the samples were degassed in vacuum at $90^{\circ} \mathrm{C}$ for $24 \mathrm{~h}$. Their specific surface areas were determined on the basis of the BET (Brunauer-Emmett-Teller) adsorption model. The total pore volumes and average pore sizes were also calculated. The pore size distributions were statistically obtained by using a Quantachrome software following BJH theory according to the desorption isotherms.

\section{Results and Discussion}

\subsection{Polymerization Kinetics}

A series of ethylene polymerization, as well as propylene polymerization, was conducted under the same conditions for different durations, and each polymerization run was quenched by adding 
TPCC when the planned reaction time was reached. The reaction products were analyzed for sulfur content, and the fraction of active centers $\left(\left[\mathrm{C}^{*}\right] /[\mathrm{Ti}]\right)$ of each polymer sample was determined based on its sulfur content. The polymerization rate $R_{\mathrm{p}}$ was determined from differentiation of the curve of polymer yield versus time. According to the rate equation $R_{\mathrm{p}}=k_{\mathrm{p}}\left[\mathrm{C}^{*}\right][\mathrm{M}]$, which has been well established for most catalyzed olefin polymerizations, the apparent chain propagation rate constant $k_{\mathrm{p}}$ was calculated using the $R_{\mathrm{p}}$ and [C $\left.\mathrm{C}^{*}\right] /[\mathrm{Ti}]$ data, as well as equilibrium monomer concentration in the reaction system. GPC analysis on the polymer samples was also carried out to determine their molecular weight distribution and average molecular weight. The results are shown in Table 1 and Figure 1, respectively.

Table 1. Kinetic parameters and polymer properties of ethylene and propylene polymerizations ${ }^{a}$.

\begin{tabular}{|c|c|c|c|c|c|c|c|c|}
\hline Run & $t_{\mathrm{p}}{ }^{b}(\mathrm{~s})$ & $\begin{array}{c}m_{\mathrm{P}} / m_{\text {Cat }} \\
{ }^{c}(\mathrm{~g} / \mathrm{g})\end{array}$ & $\begin{array}{l}\text { Activity }(\mathrm{kg} / \mathrm{g} \\
\text { Ti } \cdot \mathrm{h})\end{array}$ & $\begin{array}{l}M_{\mathrm{w}}^{d} \\
\left(10^{5}\right)\end{array}$ & $\bigoplus^{d}$ & $\begin{array}{c}R_{\mathrm{p}}\left(10^{-3}\right. \\
\mathrm{mol} / \mathrm{L} \cdot \mathrm{s})\end{array}$ & $\begin{array}{c}{\left[\mathrm{C}^{*}\right] /[\mathrm{Ti}]} \\
(\%)\end{array}$ & $\begin{array}{c}k_{\mathrm{p}} \\
(\mathrm{L} / \mathrm{mol} \cdot \mathrm{s})\end{array}$ \\
\hline E1 & 30 & 0.17 & 0.76 & 3.34 & 10.6 & $-e$ & $-e$ & $-e$ \\
\hline E2 & 60 & 0.35 & 0.78 & 3.71 & 8.1 & 0.32 & 0.20 & 2035 \\
\hline E3 & 120 & 0.65 & 0.72 & 4.26 & 16.7 & 0.48 & 0.25 & 2410 \\
\hline E4 & 180 & 1.12 & 0.83 & 5.79 & 12.6 & 0.54 & 0.49 & 1380 \\
\hline E5 & 240 & 1.67 & 0.93 & 5.51 & 9.5 & 0.45 & 0.51 & 1103 \\
\hline E6 & 480 & 2.38 & 0.66 & 5.67 & 14.0 & 0.04 & 0.55 & 85 \\
\hline E7 & 600 & 2.39 & 0.53 & 6.21 & 10.8 & 0.01 & 0.59 & 17 \\
\hline P1 & 30 & 0.36 & 1.61 & 1.51 & 5.3 & 2.27 & 0.37 & 1433 \\
\hline P2 & 60 & 1.56 & 3.48 & 1.57 & 5.7 & 2.27 & 1.50 & 356 \\
\hline P3 & 120 & 5.44 & 6.05 & 1.59 & 6.2 & 2.27 & 3.10 & 172 \\
\hline P4 & 180 & 8.05 & 5.97 & 1.49 & 5.3 & 2.27 & 3.25 & 164 \\
\hline P5 & 240 & 11.17 & 6.20 & 1.24 & 5.6 & 2.27 & 3.35 & 160 \\
\hline P6 & 480 & 25.12 & 6.98 & 1.25 & 5.3 & 2.27 & 4.51 & 118 \\
\hline P7 & 600 & 30.34 & 6.74 & 1.27 & 5.5 & 2.27 & 4.87 & 110 \\
\hline
\end{tabular}

${ }^{a}$, polymerization conditions: runs E1-E7 were ethylene polymerization and P1-P7 were propylene polymerization; $[\mathrm{Ti}]=1.0 \mathrm{mmol} / \mathrm{L}$; triethylaluminum $(\mathrm{TEA}) / \mathrm{Ti}=40(\mathrm{~mol} / \mathrm{mol}) ;$ pressure of ethylene and propylene $=1 \mathrm{~atm}$; polymerization temperature $=40^{\circ} \mathrm{C}$. Conditions of quench-labeling: 2-thiophenecarbonyl chloride (TPCC) $/ \mathrm{Al}=2.5$ $(\mathrm{mol} / \mathrm{mol})$; quenching time $=5 \mathrm{~min} ;{ }^{b}$, duration of polymerization; ${ }^{c}$, yield of polymer based on unit catalyst weight; ${ }^{d}$, weight average molecular weight $\left(M_{\mathrm{W}}\right)$ and polydispersity index $(\nexists){ }^{e}{ }^{e}$, not determined because of insufficient sample weight.
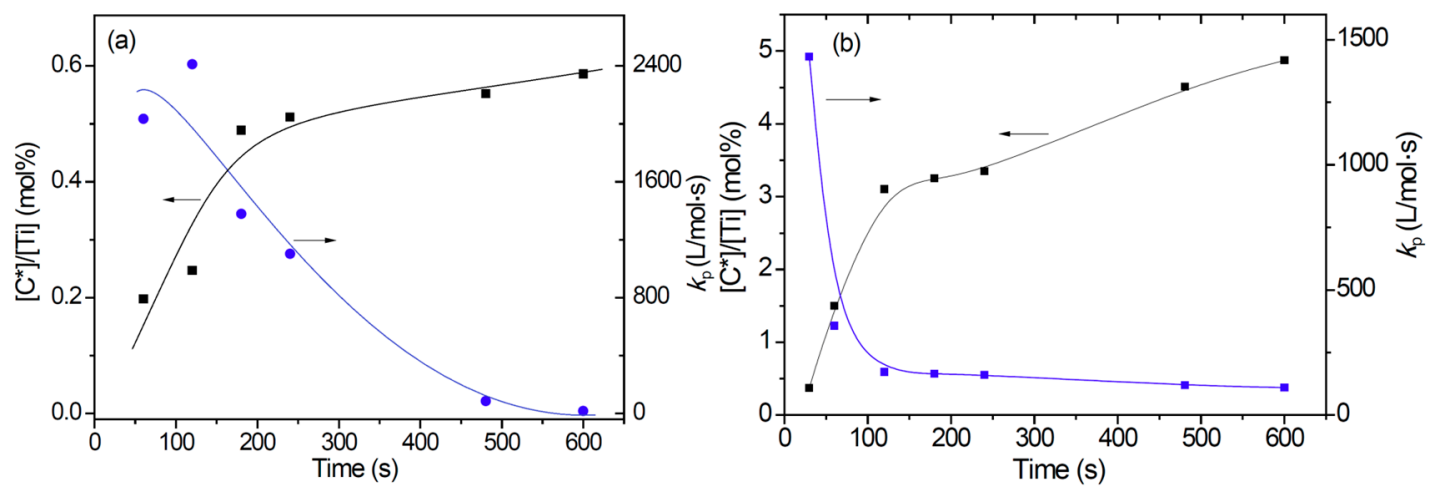

Figure 1. (a) Influence of polymerization time on the fraction of active centers and apparent propagation rate constant of ethylene polymerization; (b) influence of polymerization time on the fraction of active centers and apparent propagation rate constant of propylene polymerization.

It is seen that the activity of ethylene polymerization was noticeably lower than that of propylene polymerization in the $10 \mathrm{~min}$ reaction period. The former system experienced a moderate rise of reaction rate in the first $3 \mathrm{~min}$, but then the rate quickly decreased and fell to nearly zero activity after $10 \mathrm{~min}$. In contrast, the propylene system showed a much higher reaction rate at the very beginning and maintained it in the following $10 \mathrm{~min}$. As shown in Figure 1, the lower activity of ethylene polymerization in the first $4 \mathrm{~min}$ can be mainly attributed to its lower fraction of active centers 
compared with that of propylene polymerization. In the later stage $\left(t_{\mathrm{p}}=6-10 \mathrm{~min}\right)$, the $k_{\mathrm{p}}$ value of ethylene polymerization decreased to very low level, resulting in even lower polymerization rate.

In our previous study on ethylene polymerization kinetics with an industrial supported Z-N catalyst designed for polyethylene production, similar growth of $\left[\mathrm{C}^{*}\right] /[\mathrm{Ti}]$ with polymerization time was observed, and the growth of $\left[\mathrm{C}^{*}\right] /[\mathrm{Ti}]$ was correlated with gradual disintegration of the catalyst particles in the reaction process $[21,22,33]$. Hydraulic forces of the growing polymer phase were considered as the dominant factor in the particle fragmentation. By comparing the changes of $\left[\mathrm{C}^{*}\right] /[\mathrm{Ti}]$ with mass ratio of polymer to catalyst $\left(m_{\mathrm{P}} / m_{\text {Cat }}\right)$ in the two polymerization systems (see Figure 2 ), it is seen that both systems showed a two-stage increase of $\left[\mathrm{C}^{*}\right] /[\mathrm{Ti}]$ with $m_{\mathrm{P}} / m_{\mathrm{Cat}}$, where the first stage showed rapid growth of $\left[C^{*}\right] /[$ Ti], which slowed down but continued in the second stage. The main difference between the two systems was the much higher efficiency of particle fragmentation by polymer in the propylene system than that of the ethylene system. This means that the same amount of polymer in the ethylene system caused particle fragmentation to a much lesser extent than the propylene polymerization.

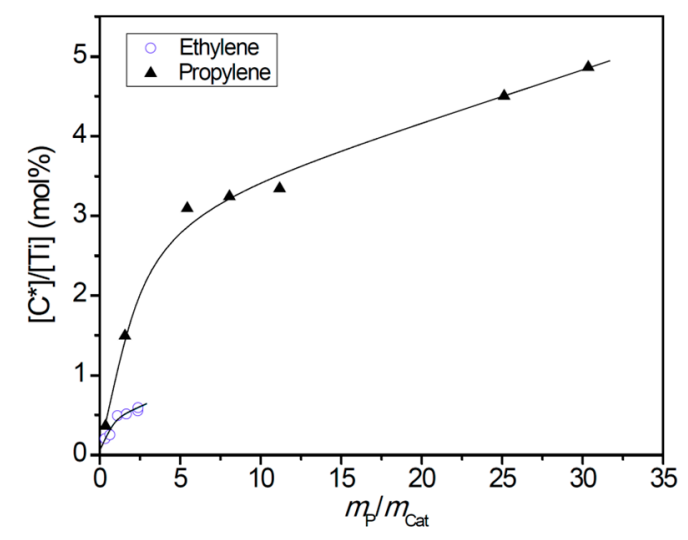

Figure 2. Changes of the fraction of active centers with polymer/catalyst mass ratio in ethylene and propylene polymerizations.

The rapid decrease of $k_{\mathrm{p}}$ value in the polymerization processes can be explained by the increase of diffusion barrier with the increase of $m_{\mathrm{P}} / m_{\text {Cat }}$ ratio, because the polymer layer surrounding the catalyst fragments where the active centers are anchored can retard mass transfer inside the polymer/catalyst particles, and reduce local monomer concentration in the particles [35-38]. For this reason, it can be assumed that the $k_{\mathrm{p}}$ value is reversely proportional to the $m_{\mathrm{P}} / m_{\text {Cat }}$ ratio. In fact, such correlation does exist when the $m_{\mathrm{P}} / m_{\text {Cat }}$ ratio increased from 0 to about 2 (see Table 1 and Figure S1 of Supplementary Materials). In propylene polymerization, the $k_{\mathrm{p}}$ value gradually leveled off after about $2 \mathrm{~min}$ of polymerization, but in ethylene polymerization, the $k_{\mathrm{p}}$ value decayed continuously until reaching zero.

The weight average molecular weight of polyethylene evidently increased with reaction time, which can be explained by the decay of a part of active centers producing low molecular weight polymer [19]. However, the molecular weight of polypropylene was kept nearly constant during the reaction period.

\subsection{Morphology of the Polymer/Catalyst Particles}

The remarkably different kinetic behaviors of ethylene and propylene polymerizations prompted us to search for more evidence that can disclose the mechanism behind the phenomena. As discussed above, the changes of $\left[\mathrm{C}^{*}\right] /[\mathrm{Ti}]$ and $k_{\mathrm{p}}$ in the polymerization process are all closely related with the polymer/catalyst particles, because these are the actual places in which the reactions take place. Research into the morphology of nascent polymer/catalyst particles may provide important information on the polymerization process. Several experimental methods have been reported in such studies. Di Martino et al. developed a quenched-flow method, in which olefin polymerization of very 
short duration is "quenched" with a poison without destroying the polymer/catalyst particles [39]. T. Taniike et al. used a similar method to fix the nascent morphology of the particles and trace their development in the polymerization process [40]. In this work, a method similar to that adopted by $\mathrm{M}$. Terano et al. [41] was used to collect nascent polymer/catalyst particles and condition them for SEM observation. Typical SEM pictures of PE/catalyst and PP/catalyst particles collected at different polymerization times are shown in Figures 3 and 4, respectively. More SEM pictures of the polymer/catalyst particles are shown in Figures S3 and S4 of Supplementary Materials. SEM pictures of the original catalyst particles are shown in Figure S2 of Supplementary Materials.
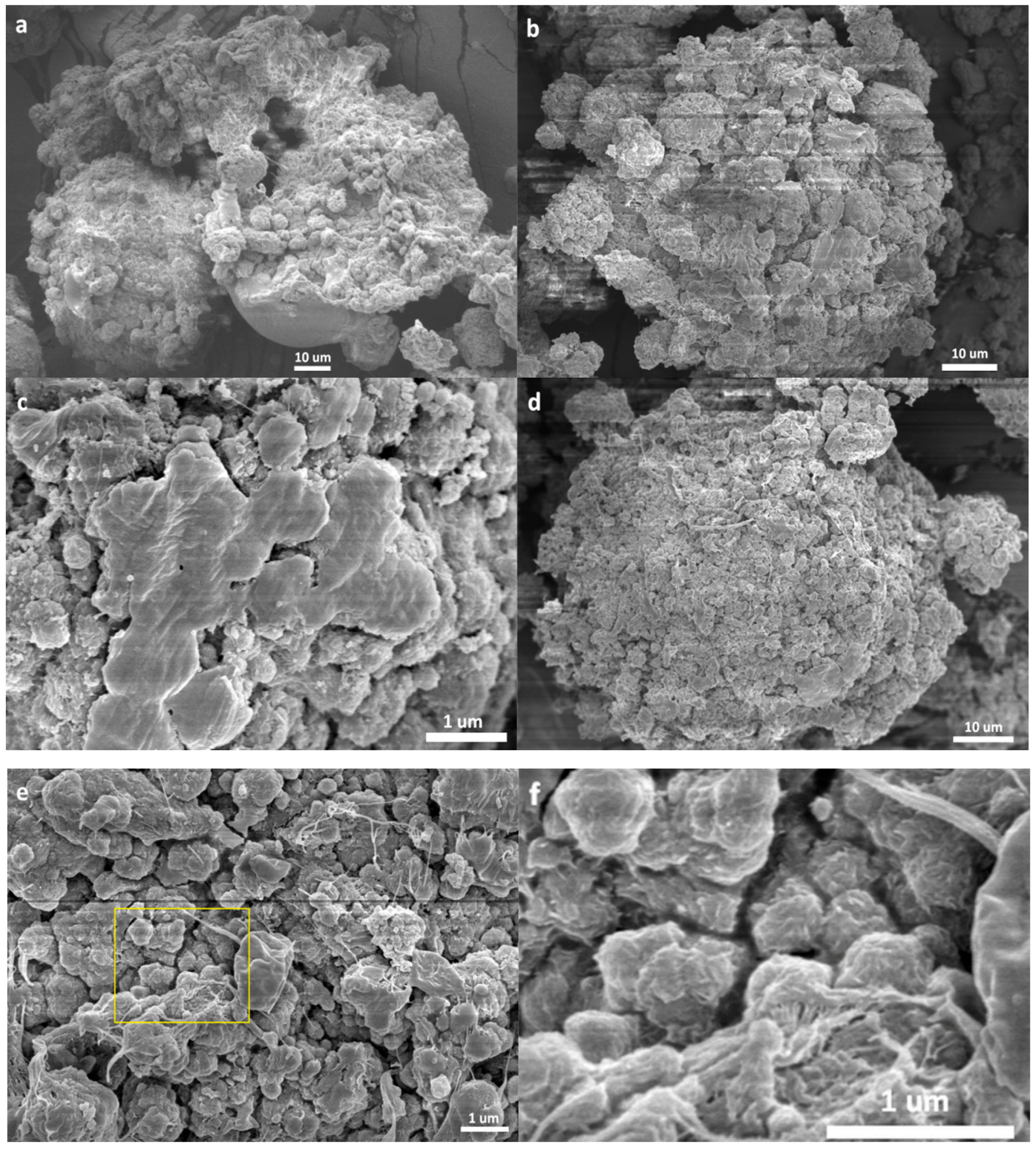

Figure 3. SEM pictures of PE/catalyst particles formed at different polymerization times: (a) $60 \mathrm{~s}$; (b,c) $120 \mathrm{~s}$; (d-f) $180 \mathrm{~s}$ (samples E2, E3, and E4 in Table 1. The enlarged picture of the marked area in (e) is shown in (f)). 

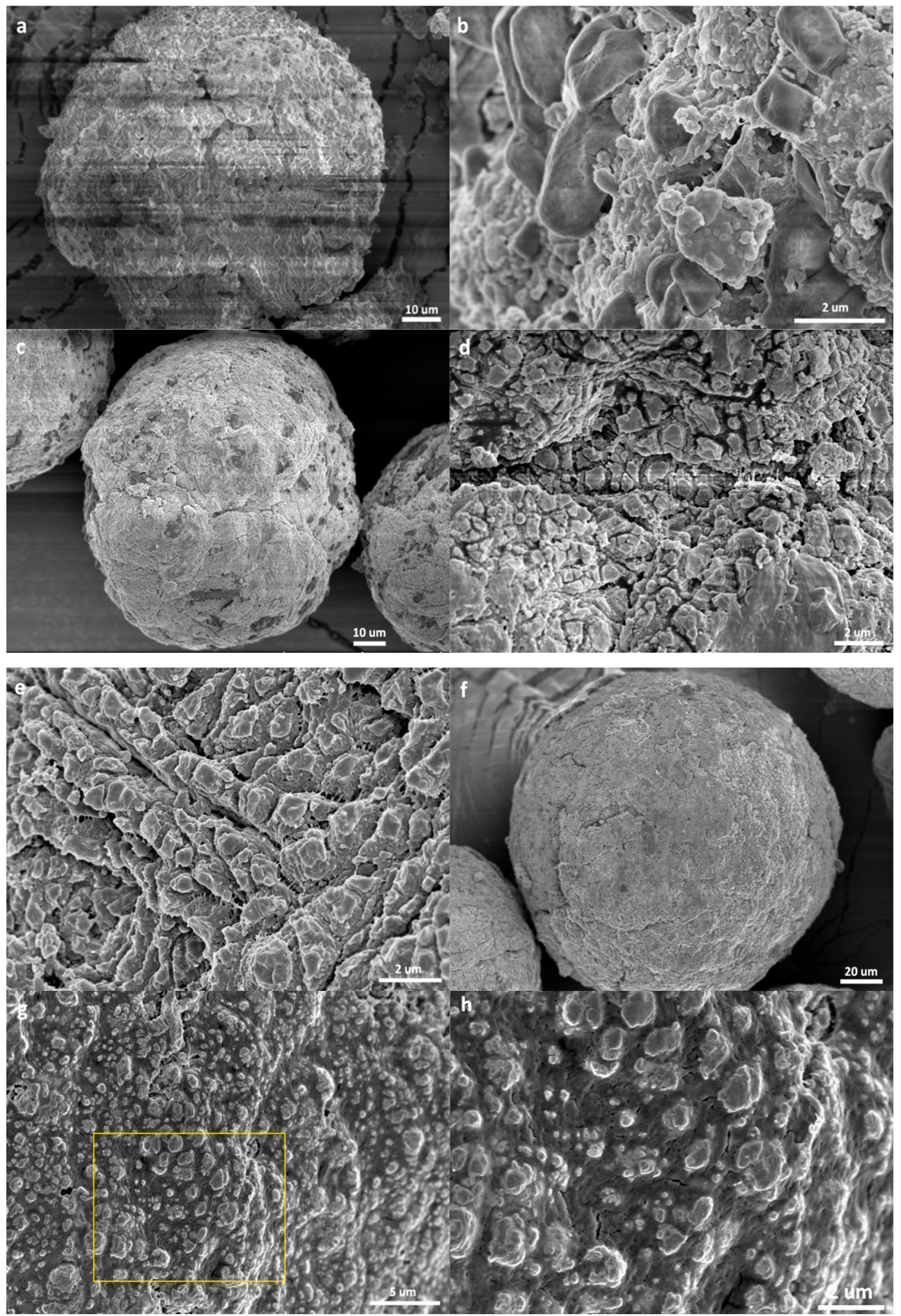

Figure 4. SEM pictures of PP/catalyst particles formed at different polymerization times: (a,b) $30 \mathrm{~s}$; (c,d) $60 \mathrm{~s}$; (e) $120 \mathrm{~s}$; (f-h) $180 \mathrm{~s}$ (samples P1, P2, P3, and P4 in Table 1).

As shown in Figure S2, the catalyst particles have a regular spherical shape with a diameter ranging from 10 to $50 \mu \mathrm{m}$. The enlarged picture of the internal part of a particle showed that the whole particle was composed of sub-particles of $150-500 \mathrm{~nm}$ in size, which are clearly divided by tiny cracks 
between them. Totally speaking, the catalyst particle has a rather compact solid structure, besides the presence of broad cracks (width $>0.1 \mu \mathrm{m}$ ) on the outer surface and the internal part.

When ethylene polymerization was conducted for short time, the nascent PE/catalyst particles presented a rather loose and porous morphology, and a part of spherical particles was seriously broken into irregular fragments. When the polymerization was extended to $3 \mathrm{~min}$, the roughly spherical particles can be found to be composed of irregular small particles of about $0.3-1.5 \mu \mathrm{m}$. By comparing with the sub-particles in the original catalyst, and considering the rather low $\mathrm{PE} /$ catalyst mass ratio $\left(1.12\right.$ at $\left.t_{\mathrm{p}}=180 \mathrm{~s}\right)$, it is likely that these small particles are composites of PE that cover the sub-particles, where the PE chains were formed by active centers of the sub-particles. Platelet structures in the small particles (see Figure 3f) can be attributed to PE crystalline lamellae.

The morphology of PP/catalyst particles (Figure 4) was noticeably different from that of $\mathrm{PE} /$ catalyst particles. As propylene polymerization proceeded from 0 to $3 \mathrm{~min}$, the spherical shape of the catalyst particles was well preserved. Similar phenomena have been well reported in the past [42-46]. After only $30 \mathrm{~s}$ of polymerization, the particle's outer surface looked like a mixture of tiny irregular polymer particles and large (1 to $2 \mu \mathrm{m})$ grains with smooth surfaces. The latter could be the solid phase of the catalyst, or an inorganic component covered by a thin polymer layer. As the polymerization continued to $60-120 \mathrm{~s}$, most of these micrometer-sized hard particles disappeared, meaning that they were disintegrated by the growing PP chains. Though there are domains with sizes of 0.5 to $2 \mu \mathrm{m}$ on the outer surface, they were intimately interconnected with each other. As the polymerization proceeded for $180 \mathrm{~s}$, the outer surface became smoother. If the micrometer-sized plateaus on the particle's outer surface seen at $t_{\mathrm{p}}=180 \mathrm{~s}$ were originated from the sub-particles of the catalyst granule, merging of their boundaries means that a large proportion of the catalyst's sub-particles underwent severe disintegration in the later stage of polymerization. By comparing Figures $3 \mathrm{~d}-\mathrm{f}$ and $4 \mathrm{f}-\mathrm{h}$, it is clear that the PE/catalyst particles are loose aggregates of sub-particles of about $0.3-1.5 \mu \mathrm{m}$, while the sub-particles in PP/catalyst particles are intimately merged with each other.

Nitrogen adsorption-desorption isotherms of the catalyst and typical polymer/catalyst nascent particles (E3, E4, P1, and P2) were measured to determine their pore size distribution curves (see Figure 5 and Figure S5 of Supplementary Materials). As seen in Figure 5a, the catalyst particles presented a strong peak at about $20 \mathrm{~nm}$ in the pore size distribution. Because the sub-particles $(150-500 \mathrm{~nm})$ in the catalyst are much larger than $20 \mathrm{~nm}$, it is likely that these tiny pores are mainly located inside the sub-particles. In the PE/catalyst particles, the number of pores around $20 \mathrm{~nm}$ was noticeably reduced to $1 / 3-1 / 4$ of those in the catalyst, but the number of larger pores $(>50 \mathrm{~nm})$ was reduced further. This is especially evident in sample E3, which has a PE/catalyst mass ratio of only 0.645. A possible explanation is that most large pores with size $>50 \mathrm{~nm}$ were filled up by the PE chains, but only a relatively smaller proportion of $20 \mathrm{~nm}$ pores were filled up after ethylene polymerization.
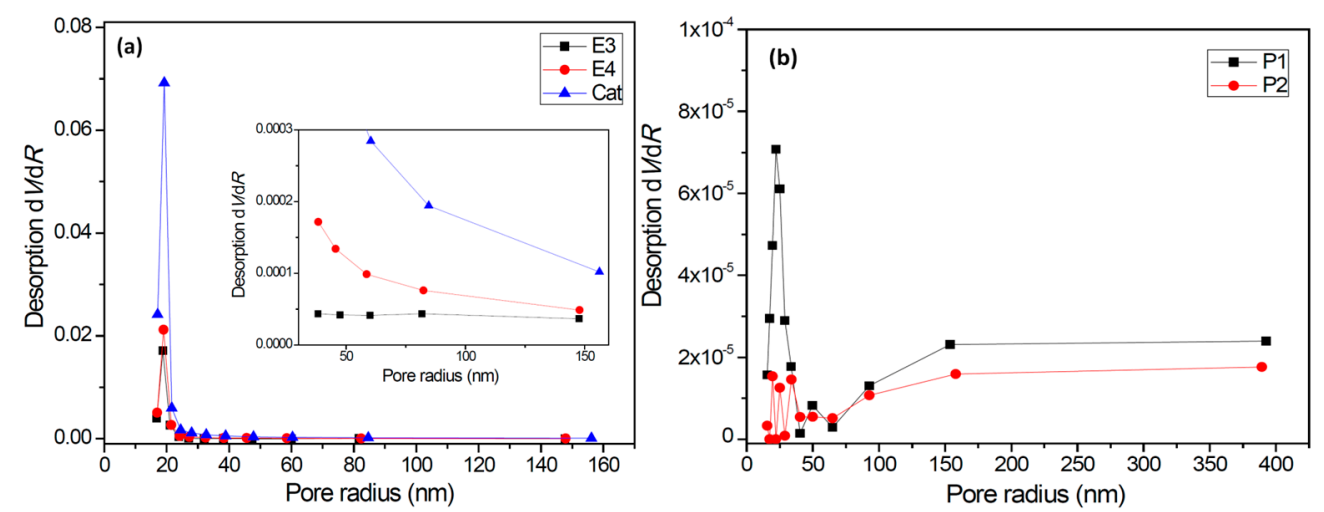

Figure 5. Pore size distributions of the catalyst and the polymer/catalyst particles. (a) Polyethylene/catalyst and catalyst and (b) polypropylene/catalyst. 
In sharp contrast with the $\mathrm{PE} /$ catalyst particles, in the $\mathrm{PP} /$ catalyst particles, the volume of the $20 \mathrm{~nm}$ pores was reduced to only about $1 / 1000$ of that in the catalyst particles when $m_{\mathrm{P}} / m_{\text {Cat }}$ was only 0.36 (sample P1), and it was further reduced to nearly zero when $m_{\mathrm{P}} / m_{\text {Cat }}$ increased to 1.56 (sample $\mathrm{P} 2$ ). The volume of larger pores in the PP/catalyst particles was also noticeably smaller than that in the $\mathrm{PE} /$ catalyst particles and the original catalyst. As shown in Table 2, the specific surface area and total pore volume decreased in the following order: catalyst particle $>\mathrm{PE}$ /catalyst particle $>>\mathrm{PP} /$ catalyst particle; meanwhile, the average pore size presented a reversed order. The PP/catalyst particles are far less porous than the PE/catalyst particles. This could be correlated to the higher $\left[\mathrm{C}^{*}\right] /[\mathrm{Ti}]$ ratio reached in propylene polymerization than in ethylene polymerization. The greater extent of catalyst fragmentation in the former system could have caused the disappearance of most of the $20 \mathrm{~nm}$ pores, and released more active sites on the exposed surfaces. PP chains produced by these active sites can than cover the exposed surfaces, forming rather compact polymer/catalyst particles.

Table 2. Structural parameters of catalyst and nascent polymer/catalyst particles.

\begin{tabular}{cccc}
\hline Sample & Specific Surface Area $\left(\mathbf{m}^{\mathbf{2}} \mathbf{g}\right)$ & Total Pore Volume $\left(\mathbf{c m}^{\mathbf{3}} \mathbf{g}\right)$ & Average Pore Size $(\mathbf{n m})$ \\
\hline Cat. & 281.55 & 0.320 & 22.37 \\
E3 & 34.84 & 0.065 & 37.95 \\
E4 & 51.85 & 0.090 & 33.36 \\
P1 & 2.79 & 0.013 & 95.80 \\
P2 & 1.55 & 0.009 & 117.44 \\
\hline
\end{tabular}

\subsection{Polymer Aggregation State in Nascent Polymer Particle}

The aggregation state of the just-formed polymer phase was analyzed by recording the first DSC heating scan on nascent polymer particles that had not been heated to melting before. As shown in Table 3 and Figure S6 of the Supplementary Materials, PE in the nascent polymer particles had a rather high melting temperature and crystallinity, while the melting temperature of the nascent PP samples was not much different from that of PP crystallized from melt. The melting temperature of the PE sample was noticeably higher than that of the same sample crystallized from melt (see Table S1 of the Supplementary Materials). Lamellar thickness distributions of the polymer samples were calculated according to the Thomson-Gibbs equation:

$$
T_{\mathrm{m}}=T_{\mathrm{m}}{ }^{\circ}\left[1-2 \sigma_{\mathrm{e}} /\left(L \times \Delta H_{f}{ }^{\circ}\right)\right],
$$

where $T_{\mathrm{m}}{ }^{\circ}$ is equilibrium melting temperature, $L$ is lamellar thickness, $\sigma_{\mathrm{e}}$ is free surface energy of the end faces at which the chains fold, and $\Delta H_{f}{ }^{\circ}$ is melting enthalpy of a perfect crystal. For calculation of the polyethylene samples, the following parameters were applied: $T_{\mathrm{m}}{ }^{\circ}=145.8^{\circ} \mathrm{C}$ [47], $\sigma_{\mathrm{e}}=90 \times 10^{-7} \mathrm{~J} / \mathrm{cm}^{2}$ [48], and $\Delta H_{f}{ }^{\circ}=289.4 \mathrm{~J} / \mathrm{cm}^{3}$ [49]. For calculation of the polypropylene samples, the following parameters were applied: $T_{\mathrm{m}}{ }^{\circ}=208.0^{\circ} \mathrm{C}[50], \sigma_{\mathrm{e}}=70 \times 10^{-7} \mathrm{~J} / \mathrm{cm}^{2}[51]$, and $\Delta H_{f}{ }^{\circ}=$ $154 \mathrm{~J} / \mathrm{cm}^{3}$ [52]. The results are shown in Figure 6. 
Table 3. Thermal properties of nascent polymer particles.

\begin{tabular}{ccccc}
\hline Run & Polymer & $\boldsymbol{T}_{\mathbf{m}}{ }^{a}\left({ }^{\circ} \mathbf{C}\right)$ & $\Delta \boldsymbol{H}_{\mathbf{f}}{ }^{\boldsymbol{b}}(\mathbf{J} / \mathbf{g})$ & $\boldsymbol{X}_{\mathbf{c}}{ }^{c}(\%)$ \\
\hline E1 & & 139.5 & 228.8 & 79.4 \\
E2 & PE & 140.1 & 208.5 & 72.4 \\
E3 & & 139.9 & 201.1 & 69.8 \\
E4 & & 141.8 & 200.7 & 69.7 \\
\hline P1 & & 161.0 & 86.7 & 56.3 \\
P2 & PP & 161.6 & 83.4 & 54.2 \\
P3 & & 161.0 & 79.8 & 51.8 \\
P4 & & 161.1 & 69.2 & 44.9 \\
\hline
\end{tabular}

${ }^{a}$, melting temperature; ${ }^{b}$, melting enthalpy; ${ }^{c}$, degree of crystallization calculated based on $100 \%$ defect free polyethylene crystal with a $289 \mathrm{~J} / \mathrm{g}$ fusion heat [49] and polypropylene crystal with a $154 \mathrm{~J} / \mathrm{g}$ fusion heat [52].
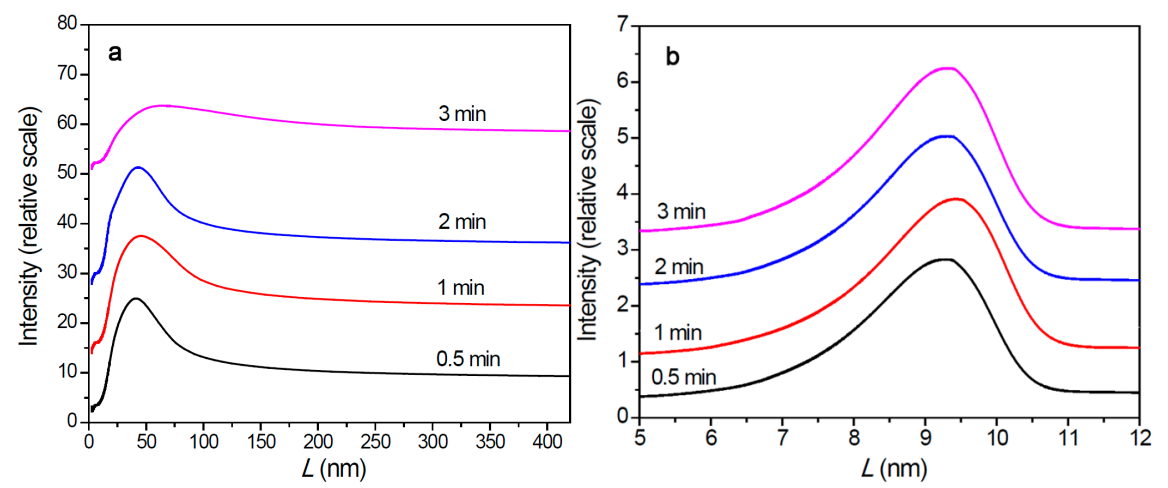

Figure 6. Lamellar thickness distribution of nascent polymer collected at different polymerization time.

(a) Polyethylene and (b) polypropylene.

The two series of polymers showed significantly different lamellar thickness distributions. Lamellar thickness of the PE samples was distributed in the size range of larger than $20 \mathrm{~nm}$, with the peak values appearing at about $40 \mathrm{~nm}$. However, the PP samples showed rather narrow lamellar thickness distributions, with the peak values appearing at about $9 \mathrm{~nm}$. There were almost no lamellae thicker than $11 \mathrm{~nm}$ in the PP samples. By comparing with pore size distributions of the catalyst and polymer/catalyst particles (Figure 5), we can find that formation of PP lamellae inside the $20 \mathrm{~nm}$ pores of the catalyst particles is possible, but PE lamellae cannot grow inside these small pores because of their much larger thickness.

On the basis of the results of polymerization kinetics, solid structure of polymer/catalyst particles, and polymer aggregation state in the nascent particles, we can propose a mechanistic model to reasonably explain the distinct kinetic behaviors between ethylene and propylene polymerizations with the same supported $\mathrm{Z}-\mathrm{N}$ catalyst, which is described in the following points:

1. Changes of active center concentration in the initial stage (0-10 min) clearly show that the lower rate of ethylene polymerization compared with that of propylene can be attributed to a much slower build-up of $\left[\mathrm{C}^{*}\right]$ in the former system.

2. Both polymerization systems experienced a similar degree of diffusion limitation in the first 0-3 min, as shown by the larger apparent propagation rate constant in ethylene polymerization and similar slopes of the $k_{\mathrm{p}}$ versus $m_{\mathrm{P}} / m_{\text {Cat }}$ curves. The porosity of PE/catalyst particles was larger than that of the $\mathrm{PP} /$ catalyst particles. The lower activity of ethylene polymerization cannot be attributed to its stronger diffusion limitation.

3. The catalyst particles have rather compact solid structure, though they are composed of sub-particles with a size of about $200-500 \mathrm{~nm}$, and there are cracks with widths ranging from $100 \mathrm{~nm}$ to $5 \mu \mathrm{m}$. Pore size distribution, determined by the nitrogen adsorption method, shows that the nanometer pores in the catalyst are concentrated in the range of $15-25 \mathrm{~nm}$. There is a 
huge number of such small pores, which renders the catalyst a very large specific surface area $\left(282 \mathrm{~m}^{2} / \mathrm{g}\right)$ and high porosity $\left(0.32 \mathrm{~cm}^{3} / \mathrm{g}\right)$. These $20 \mathrm{~nm}$ pores should be uniformly scattered in the solid phase of the catalyst. Assuming that the sub-particles are dense cubes with edges of $200 \mathrm{~nm}$ and a density of $2.34 \mathrm{~g} / \mathrm{cm}^{3}$ (density of $\mathrm{MgCl}_{2}$ crystal), their aggregate will have a specific surface area of $13 \mathrm{~m}^{2} / \mathrm{g}$, which is far lower than the measured specific surface area. The measured value of $282 \mathrm{~m}^{2} / \mathrm{g}$ will correspond to $\mathrm{MgCl}_{2}$ crystallite size (length of cube edges) of about $9 \mathrm{~nm}$. This size is quite close to that of $\mathrm{MgCl}_{2}$ crystallites $(7 \mathrm{~nm})$ in supported Z-N catalysts determined by E. Redzic et al. [53]. Therefore, the 200-500 nm sub-particles cannot be dense solid, but rather aggregates of smaller $\mathrm{MgCl}_{2}$ crystallites containing many nanopores. It is likely that there is a large number of pores and cracks of about $20 \mathrm{~nm}$ in the sub-particles.

4. Because the sizes of PE lamellae formed by the growing polymer chains are far larger than the size of nanopores in the catalyst's sub-particles, these lamellae cannot grow inside the nanopores, leaving the porous sub-particles basically intact during ethylene polymerization. Only the active sites exposed on the outer surface of the sub-particles can be activated and work as catalytic centers, but a large proportion of active site precursors is buried in the sub-particles and thus becomes unavailable to the polymerization reaction, resulting in a low $\left[\mathrm{C}^{*}\right] /[\mathrm{Ti}]$ ratio of ethylene polymerization. With the proceeding of polymerization, the PE layer covering the sub-particle will form a diffusion barrier that grows quickly with the increase of the $m_{\mathrm{P}} / m_{\text {Cat }}$ ratio, and finally leads to ceasing of the polymerization.

5. In the propylene polymerization system, the PP lamellae with a size of 6-11 nm can enter the $20 \mathrm{~nm}$ pores in the sub-particles. Growth of these PP lamellae in the pores can exert hydraulic forces strong enough to break up the sub-particles and release their buried active site precursors. Subsequently, the $20 \mathrm{~nm}$ pores in the sub-particles will disappear, and the exposed surfaces carrying active sites will be covered by PP chains. After a short period of time, the whole polymer/catalyst particle will become rather compact, and the texture of the particle becomes rather smooth. Though the PP layer covering the $\mathrm{MgCl}_{2}$ crystallites (carrier of the active sites) can also cause serious diffusion barrier, for the much higher density of active sites in this system compared with the ethylene polymerization, the dynamically renewed carrier surface can allow for the presence of tiny pores in the PP layer. This will enable slow but stable diffusion of monomer stream in the PP layer, and a stable polymerization rate supported by a high $\left[\mathrm{C}^{*}\right] /[\mathrm{Ti}]$ ratio and low apparent rate constant.

This explanation is still far from comprehensive, but as we believe, it is the most reasonable one based on the present experimental results. According to this mechanism, fragmentation of the catalyst particles in the initial stage of polymerization is the decisive factor that determines the $\left[\mathrm{C}^{*}\right] /[\mathrm{Ti}]$ fraction, and thus the catalyst's productivity, reachable in the main reaction stage. In the case of olefin polymerizations forming crystalline polymers, the difference between lamellar thickness of the polymer phase and pore size in the catalyst particle is also a key factor. Growth of thin polymer lamellae inside the nano-sized pores can cause further fragmentation of the sub-particles and exposure of more active sites. When the polymer chains form lamellae thicker than the pore size in the sub-particles, the lamellae tend to grow in space out of the nanopores in order to avoid the space confinement effects that require extra energy. It is thus expected that factors leading to reduction of lamellar thickness will promote fragmentation of the catalyst particles and enhance the catalytic activity. Enhancement of ethylene polymerization activity by prepolymerization with propylene can be explained by enhanced particle fragmentation in the prepolymerization stage. The comonomer activation effect in ethylene/ $\alpha$-olefin copolymerization [31] can also be explained by enhancement of particle fragmentation, because lamellar thickness of copolymer is evidently smaller than that of ethylene homopolymer [53,54]. On the other side, $\mathrm{MgCl}_{2}$-supported $\mathrm{Z}-\mathrm{N}$ catalysts with average pore size far larger than $20 \mathrm{~nm}$ are found to have a rather high $\left[\mathrm{C}^{*}\right] /[\mathrm{Ti}]$ ratio in ethylene polymerization [23], or show ethylene polymerization activity much higher than the level reported in this work [55]. However, the presence of the soft amorphous phase (which is always present in 
PE or PP particles) in the nascent polymer will make the real mechanism more complicated than the simplified mechanism discussed here. J. Loos et al. found that catalyst fragmentation in propylene polymerization with the Z-N catalyst was slowed down by introducing ethylene as a comonomer [56]. It seems that the hard crystalline lamellae, for their low mobility, are more effective than the amorphous phase in expanding the nanopores and breaking the catalyst. More experimental and theoretical studies are expected to fully disclose the mechanism of initial polymerization kinetics and fragmentation of catalyst particles.

\section{Conclusions}

Homopolymerizations of ethylene and propylene with the same $\mathrm{MgCl}_{2}$-supported $\mathrm{Z}-\mathrm{N}$ catalyst containing an internal electron donor showed remarkably different kinetic behaviors. Activity of ethylene polymerization was about $75 \%$ lower than that of propylene, and the polymerization rate quickly decayed with time in the former system, in contrast to a stable $R_{\mathrm{p}}$ versus time profile in the latter. The ethylene system showed a very low $\left[C^{*}\right] /[$ Ti] ratio $(<0.6 \%)$ in the 10 min reaction process, in contrast to a much higher $\left[\mathrm{C}^{*}\right] /[\mathrm{Ti}]$ ratio $(1.5 \%-4.9 \%)$ in propylene polymerization. The two systems showed noticeably different morphologies of the nascent polymer/catalyst particles, with the PP/catalyst particles being more compact and homogeneous than the PE/catalyst particles. On the basis of the observed phenomena, the different kinetic behaviors of the two reaction systems can be explained by faster and more sufficient catalyst fragmentation in propylene polymerization than in the ethylene system. In the propylene system, a large proportion of active sites was exposed through catalyst particle fragmentation in the polymerization process, but the degree of particle fragmentation was remarkably lower in the ethylene system. The larger thickness of PE lamellae in the nascent polymer than the average size of nano-pores in the catalyst is considered the main reason for the low efficiency of particle fragmentation in the ethylene system. In contrast, for the smaller lamellar thickness $(<20 \mathrm{~nm})$ of PP compared with the size of nanopores $(15-25 \mathrm{~nm})$ in the catalyst, PP lamellae may grow inside the nanopores and break up the catalyst particles by their hydraulic forces. The importance of catalyst fragmentation in fully releasing active site precursors in the catalyst and realizing high polymerization activity is clearly manifested in this work. Matching between the polymer's lamellar thickness and size of the catalyst's nanopores is an important factor that determines the efficiency of catalyst fragmentation.

Supplementary Materials: The following are available online at http:/ / www.mdpi.com/2073-4360/11/2/358/s1. Figure S1: Changes of apparent rate constant with polymer/catalyst mass ratio; Figure S2: SEM pictures of catalyst particles; Figure S3: SEM pictures of polyethylene/catalyst particles at different polymerization times; Figure S4: SEM pictures of polypropylene/catalyst particles at different polymerization times; Figure S5: Nitrogen adsorption-desorption isotherms of polymer/catalyst particles; Figure S6: DSC curves of PE and PP samples (the first heating scan); Table S1: Thermal Properties of Polymer Samples Based on the Second Heating Scan.

Author Contributions: Conceptualization, Z.F. (Zhiqiang Fan), Z.Z., and J.X.; methodology, Z.F. (Zhiqiang Fan), Z.Z., and Z.F. (Zhisheng Fu); software, B.J. and F.H.; formal analysis, Z.Z.; writing一original draft preparation, Z.Z.; writing-review and editing, Z.F. (Zhiqiang Fan).

Funding: This research was funded by National Natural Science Foundation of China (Grant No. 51773178 and 21374094).

Conflicts of Interest: The authors declare no conflict of interest.

\section{References}

1. Keii, T.; Terano, M.; Kimura, K.; Ishii, K. A kinetic argument for a quasi-living polymerization of propene with a $\mathrm{MgCl}_{2}$-supported catalyst. Macromol. Chem. Rapid Commun. 1987, 8, 583-587. [CrossRef]

2. Marques, M.M.V.; Nunes, C.P.; Tait, P.J.T.; Dias, A.R. Polymerization of ethylene using a high-activity Ziegler-Natta catalyst. 1. Kinetic studies. J. Polym. Sci. Part A 1993, 31, 209-218. [CrossRef]

3. Fan, Z.; Feng, L.; Yang, S. Distribution of active centers on $\mathrm{TiCl}_{4} / \mathrm{MgCl}_{2}$ catalyst for olefin polymerization. J. Polym. Sci. Part A 1996, 34, 3329-3335. [CrossRef] 
4. Han-Adebekun, G.C.; Hamba, M.; Ray, W.H. Kinetic study of gas phase olefin polymerization with a $\mathrm{TiCl}_{4} / \mathrm{MgCl}_{2}$ catalyst I. Effect of polymerization conditions. J. Polym. Sci. Part A 1997, 35, $2063-2074$. [CrossRef]

5. Wu, L.; Lynch, D.T.; Wanke, S.E. Kinetics of gas-phase ethylene polymerization with morphology-controlled $\mathrm{MgCl}_{2}$-supported $\mathrm{TiCl}_{4}$ catalyst. Macromolecules 1999, 32, 7990-7998. [CrossRef]

6. Kissin, Y.V.; Mink, R.I.; Nowlin, T.E. Ethylene polymerization reactions with Ziegler-Natta catalysts. I. Ethylene polymerization kinetics and kinetic mechanism. J. Polym. Sci. Part A 1999, 37, 4255-4272. [CrossRef]

7. Pimplapure, M.S.; Zheng, X.; Loos, J.; Weickert, G. Low-Rate Propylene Slurry Polymerization: Morphology and Kinetics. Macromol. Rapid. Commun. 2005, 26, 1155-1158. [CrossRef]

8. Mirzaei, A.; Vakili, M.; Tafi, N. Prepolymerization of ethylene with a Ziegler-Natta catalyst. J. Appl. Polym. Sci. 2007, 105, 2703-2711. [CrossRef]

9. Chen, K.; Liu, B.; Soares, J.B.P. Effect of prepolymerization on the kinetics of ethylene polymerization and ethylene/1-hexene copolymerization with a Ziegler-Natta Catalyst in slurry reactors. Macromol. React. Eng. 2016, 10, 463-478. [CrossRef]

10. McKenna, T.F.L.; Tioni, E.; Ranieri, M.M.; Alizadeh, A.; Boisson, C.; Monteil, V. Catalytic olefin polymerisation at short times: Studies using specially adapted reactors. Can. J. Chem. Eng. 2013, 91, 669-686. [CrossRef]

11. Fisch, A.G.; Santos, J.H.Z.D.; Secchi, A.R.; Cardozo, N.S.M. Heterogeneous catalysts for olefin polymerization: Mathematical model for catalyst particle fragmentation. Ind. Eng. Chem. Res. 2015, 54, 11997-12010. [CrossRef]

12. Skoumal, M.; Cejpek, I.; Cheng, C.P. Diffusion interface technique for determination of initial polymerization kinetics. Macromol. Rapid Commun. 2005, 26, 357-360. [CrossRef]

13. Heuvelsland, A.; Wichmann, S.; Schellenberg, J. Investigations of the initial state polymerization of propylene with Ziegler-Natta catalysts in slurry. J. Appl. Polym. Sci. 2007, 106, 354-359. [CrossRef]

14. Machado, F.; Lima, E.L.; Pinto, J.C.; McKenna, T.F. Evaluation of the initial stages of gas-phase ethylene polymerizations with a $\mathrm{SiO}_{2}$-supported Ziegler-Natta catalyst. Macromol. React. Eng. 2009, 3, 47-57. [CrossRef]

15. Dwivedi, S.; Taniike, T.; Terano, M. Understanding the chemical and physical transformations of a Ziegler-Natta catalyst at the initial stage of polymerization kinetics: The key role of alkylaluminum in the catalyst activation process. Macromol. Chem. Phys. 2014, 215, 1698-1706. [CrossRef]

16. Yu, Y.; Busico, V.; Budzelaar, P.H.M.; Vittoria, A.; Cipullo, R. Of poisons and antidotes in polypropylene catalysis. Angew. Chem. Intl. Ed. 2016, 55, 8590-8594. [CrossRef] [PubMed]

17. Taniike, T.; Sano, S.; Ikeya, M.; Thang, V.Q.; Terano, M. Development of a large-scale stopped-flow system for heterogeneous olefin polymerization kinetics. Macromol. React. Eng. 2012, 6, 275-279. [CrossRef]

18. Mori, H.; Yoshitome, M.; Terano, M. Investigation of a fine-grain MgC12-supported Ziegler catalyst by stopped-flow propene polymerization: model for the formation of active sites induced by catalyst fragmentation during polymerization. Macromol. Chem. Phys. 1997, 198, 3207-3214. [CrossRef]

19. Kissin, Y.V. Multicenter nature of titanium-based Ziegler-Natta catalysts: Comparison of ethylene and propylene polymerization reactions. J. Polym. Sci. Part A 2003, 41, 1745-1758. [CrossRef]

20. Kissin, Y.V. Active centers in Ziegler-Natta catalysts: Formation kinetics and structure. J. Catal. 2012, 292, 188-200. [CrossRef]

21. Khan, A.; Guo, Y.; Fu, Z.; Fan, Z. Kinetics of short-duration ethylene polymerization with $\mathrm{MgCl}_{2}$-supported Ziegler-Natta catalyst: Two-stage initiation evidenced by changes in active center concentration. J. Appl. Polym. Sci. 2017, 134, 45187:1-45187:6. [CrossRef]

22. Khan, A.; Guo, Y.; Zhang, Z.; Ali, A.; Fu, Z.; Fan, Z. Kinetics of short-duration ethylene-propylene copolymerization with $\mathrm{MgCl}_{2}$-supported Ziegler-Natta catalyst: Differentiation of active centers on the external and internal surfaces of the catalyst particles. J. Appl. Polym. Sci. 2018, 135, 46030:1-460301:8. [CrossRef]

23. Jiang, B.; Weng, Y.; Zhang, S.; Zhang, Z.; Fu, Z.; Fan, Z. Kinetics and mechanism of ethylene polymerization with $\mathrm{TiCl}_{4} / \mathrm{MgCl}_{2}$ model catalysts: Effects of titanium content. J. Catal. 2018, 360, 57-65. [CrossRef]

24. Nitta, T.; Liu, B.; Nakatani, H.; Terano, M. Formation, deactivation and transformation of stereospecific active sites on $\mathrm{TiCl}_{4} /$ dibutylphthalate $/ \mathrm{Mg}(\mathrm{OEt})_{2}$ catalyst induced by short time reaction with Al-alkyl cocatalyst. J. Mol. Catal. A 2002, 180, 25-34. [CrossRef] 
25. Zakharov, V.A.; Bukatov, G.D.; Barabanov, A.A. Recent data on the number of active centers and propagation rate constants in olefin polymerization with supported ZN catalysts. Macromol. Symp. 2004, 213, 19-28. [CrossRef]

26. Qi, M.; Zhang, B.; Fu, Z.; Xu, J.; Fan, Z. Millimeter-size polyethylene hollow spheres synthesized with $\mathrm{MgCl}_{2}$-supported Ziegler-Natta catalyst. J. Appl. Polym. Sci. 2016. [CrossRef]

27. Fu, Z.; Xu, J.; Zhang, Y.; Fan, Z. Chain Structure and mechanical properties of polyethylene/polypropylene/poly(ethylene-co-propylene) in-reactor alloys synthesized with spherical Ziegler-Natta catalyst by gas-phase polymerization. J. Appl. Polym. Sci. 2005, 97, 640-647. [CrossRef]

28. Fu, Z.; Fan, Z.; Zhang, Y.; Xu, J. Chain structure of polyethylene/polypropylene in-reactor alloy synthesized in gas phase with spherical Ziegler-Natta catalyst. Polym. Int. 2004, 53, 1169-1175. [CrossRef]

29. Shen, X.; Hu, J.; Fu, Z.; Lou, J.; Fan, Z. Counting the number of active centers in $\mathrm{MgCl}_{2}$-supported Ziegler-Natta catalysts by quenching with 2-thiophenecarbonyl chloride and study on the initial kinetics of propylene polymerization. Catal. Commun. 2013, 30, 66-69. [CrossRef]

30. Shen, X.; Fu, Z.; Hu, J.; Wang, Q.; Fan, Z. Mechanism of propylene polymerization with $\mathrm{MgCl}_{2}$-supported Ziegler-Natta catalysts based on counting of active centers: The role of external electron donor. J. Phys. Chem. C 2013, 117, 15174-15182. [CrossRef]

31. Xu, T.; Yang, H.; Fu, Z.; Fan, Z. Effects of comonomer on active center distribution of $\mathrm{TCl}_{4} / \mathrm{MgCl}_{2}-\mathrm{AlEt}_{3}$ catalyst in ethylene/1-hexene copolymerization. J. Organomet. Chem. 2015, 798, 328-334. [CrossRef]

32. Guo, Y.; Zhang, Z.; Guo, W.; Khan, A.; Fu, Z.; Xu, J.; Fan, Z. Kinetics and mechanism of metallocene catalyzed olefin polymerization: Comparison of ethylene, propylene homopolymerizations and their copolymerization. J. Polym. Sci. Part A 2017, 55, 867-875. [CrossRef]

33. Yang, P.; Fu, Z.; Fan, Z. 1-Hexene polymerization with supported Ziegler-Natta catalyst: Correlation between catalyst particle disintegration and active center distribution. Mol. Catal. 2018, 447C, 13-20. [CrossRef]

34. Guo, Y.; Yang, P.; Zhang, S.; Jiang, B.; Khan, A.; Zhu, L.; Fu, Z.; Fan, Z. Study on 2-thiophenecarbonyl chloride-quenched olefin polymerization with $\alpha$-diimine nickel catalysts. Iran. Polym. J. 2018, 27, 153-159. [CrossRef]

35. Floyd, S.; Choi, K.Y.; Taylor, T.W.; Ray, W.H. Polymerization of olefins through heterogeneous catalysis. III. Polymer particle modelling with an analysis of intraparticle heat and mass transfer effects. J. Appl. Polym. Sci. 1986, 32, 2935-2960. [CrossRef]

36. Floyd, S.; Mann, G.E.; Ray, W.H. Heat and Mass Transfer Limitations and Catalyst Deactivation Effects in Olefin Polymerization for Gas Phase and Slurry Reactors. In Studies in Surface Science and Catalysis; Keii, T., Soga, K., Eds.; Elsevier: Amsterdam, The Netherlands, 1986; Volume 25, pp. 339-367.

37. Soga, K.; Ohgizawa, M.; Shiono, T.; Lee, D.H. Possibility of mass-transfer resistance in ethylene polymerization with magnesium chloride-supported catalysts. Macromolecules 1991, 24, 1699-1700. [CrossRef]

38. McKenna, T.F.; Soares, J.B.P. Single particle modelling for olefin polymerization on supported catalysts: A review and proposals for future developments. Chem. Eng. Sci. 2001, 56, 3931-3949. [CrossRef]

39. Di Martino, A.; Weickert, G.; McKenna, T.F.L. Contributions to the experimental investigation of the nascent polymerisation of ethylene on supported catalysts. 1. Macromol. React. Eng. 2007, 1, 165-184. [CrossRef]

40. Taniike, T.; Thang, V.Q.; Binh, N.T.; Hiraoka, Y.; Uozumi, T.; Terano, M. Initial particle morphology development in Ziegler-Natta propylene polymerization tracked with stopped-flow technique. Macromol. Chem. Phys. 2011, 212, 723-729. [CrossRef]

41. Thang, V.Q.; Taniike, T.; Umemori, M.; Ikeya, M.; Hiraoka, Y.; Nghia, N.D.; Terano, M. New quenching procedure for preservation of initial polymer/catalyst particle morphology in Ziegler-Natta olefin polymerization. Macromol. React. Eng. 2009, 3, 467-472. [CrossRef]

42. Galli, P.; Haylock, J.C. Advances in Ziegler-Natta polymerization-Unique polyolefin copolymers, alloys and blends made directly in the reactor. Makromol. Chem. Macromol. Symp. 1992, 63, 19-54. [CrossRef]

43. Cecchin, G.; Marchetti, E.; Baruzzi, G. On the mechanism of polypropene growth over $\mathrm{MgCl}_{2} / \mathrm{TiCl}_{4}$ catalyst systems. Macromol. Chem. Phys. 2001, 202, 1987-1994. [CrossRef]

44. Fan, Z.; Zhang, Y.; Xu, J.; Wang, H.; Feng, L. Structure and properties of polypropylene/poly(ethylene-co-propylene) in-situ blends synthesized by spherical Ziegler-Natta catalyst. Polymer 2001, 42, 5559-5566. [CrossRef] 
45. Mehtarani, R.; Fu, Z.; Tu, S.; Fan, Z.; Tian, Z.; Feng, L. Synthesis of polypropylene/poly(ethylene-co-propylene) in-reactor alloys by periodic switching polymerization process-Dynamic change of gas phase monomer composition and its influences on polymer structure and properties. Ind. Eng. Chem. Res. 2013, 52, 9775-9782. [CrossRef]

46. Mehtarani, R.; Fu, Z.; Fan, Z.; Tu, S.; Feng, L. Synthesis of polypropylene/poly(ethylene-co-propylene) in-reactor alloys by periodic switching polymerization process-Effects of gas-phase polymerization time on polymer properties. Ind. Eng. Chem. Res. 2013, 52, 13556-13563. [CrossRef]

47. Flory, P.J.; Vrij, A. Melting points of linear-chain homologs. The normal paraffin hydrocarbons. J. Am. Chem. Soc. 1963, 85, 3548-3553. [CrossRef]

48. Hoffman, J.D.; Miller, R.L. Kinetic of crystallization from the melt and chain folding in polyethylene fractions revisited: Theory and experiment. Polymer 1997, 38, 3151-3212. [CrossRef]

49. Mirabella, F.M.; Bafna, A. Determination of the crystallinity of polyethylene/ $\alpha$-olefin copolymers by thermal analysis: Relationship of the heat of fusion of $100 \%$ polyethylene crystal and the density. J. Polym. Sci. B 2002, 40, 1637-1643. [CrossRef]

50. Fatou, J.G. Melting temperature and enthalpy of isotactic polypropylene. Eur. Polym. J. 1971, 7, 1057-1064. [CrossRef]

51. Cheng, S.Z.D.; Janimak, J.J.; Zhang, A.; Cheng, H.N. Regime transitions in fractions of isotactic polypropylene. Macromolecules 1990, 23, 298-303. [CrossRef]

52. Grebowicz, J.; Lau, S.F.; Wunderlich, B. The thermal properties of polypropylene. J. Polym. Sci. Polym. Symp. 1984, 71, 19-37. [CrossRef]

53. Lu, L.; Alamo, R.G.; Mandelkern, L. Lamellar thickness distributions in linear polyethylene and ethylene copolymers. Macromolecules 1994, 27, 6571-6576. [CrossRef]

54. Rashedi, R.; Sharif, F. Variation of comonomer content in LLDPE particles with different sizes from an industrial fluidized bed reactor. Ind. Eng. Chem. Res. 2015, 54, 9870-9876. [CrossRef]

55. Xue, B.; Hui, L.; Yang, H.; Zhao, Y.; Hou, L.; Li, W. Immobilization of Ziegler-Natta catalyst for ethylene polymerization on macropores $\mathrm{SiO}_{2}$ with an open-framework structure. Ind. Eng. Chem. Res. 2017, 56, 135-142. [CrossRef]

56. Zheng, X.; Pimplapure, M.S.; Weickert, G.; Loos, J. Influence of copolymerization on fragmentation behavior using Ziegler-Natta catalysts. Macromol. Rapid Commun. 2006, 27, 15-20. [CrossRef] 